\title{
Medication adherence and survival among hospitalized heart failure patients in a tertiary hospital in Tanzania: a prospective cohort study
}

Pedro Pallangyo ${ }^{1,2^{*}} \mathbb{0}$, Jalack Millinga ${ }^{3}$, Smita Bhalia ${ }^{2}$, Zabella Mkojera ${ }^{1}$, Nsajigwa Misidai ${ }^{1}$, Happiness J. Swai ${ }^{1}$, Naairah R. Hemed ${ }^{1}$, Alice Kaijage ${ }^{2}$ and Mohamed Janabi²

\begin{abstract}
Objective: Management of heart failure is complex and multifaceted but adherence to medications remains the cornerstone of preventing avoidable readmissions, premature deaths, and unnecessary healthcare expenses. Despite of evidence-based efficacy on anti-failure drugs, poor adherence is pervasive and remains a significant barrier to improving clinical outcomes in heart failure population.

Results: We enrolled 459 patients with diagnosis of heart failure admitted at a tertiary cardiovascular hospital in Dar es Salaam, Tanzania. The mean age was 46.4 years, there was a female predominance (56.5\%), 67.5\% resided in urban areas and $74.2 \%$ had primary education. Of the 419 participants eligible for assessment of medication adherence, 313 (74.7\%) had poor adherence and 106 (25.3\%) had good adherence. Possession of a health insurance was found to be the strongest associated factor for adherence (adjusted OR 8.7, 95\% Cl 4.7-16.0, $\mathrm{p}<0.001$ ). Participants with poor adherence displayed a 70\% increased risk for rehospitalization compared to their counterparts with good adherence (adjusted RR 1.7, 95\% Cl 1.2-2.9, $\mathrm{p}=0.04$ ). Poor adherence was found to be the strongest predictor of early mortality (HR 2.5, 95\% Cl 1.3-4.6, p<0.01). In conclusion, Poor medication adherence in patients with heart failure is associated with increased readmissions and mortality.
\end{abstract}

Keywords: Heart failure, Nonadherence, Poor adherence, Low adherence, Drug adherence, Medication adherence, Medication compliance, Noncompliance, Tanzania

\section{Introduction}

Cardiovascular disorders (CVD) are responsible for about one-third of all global mortality with over threequarters of deaths transpiring in the developing world [1]. In spite of the remarkable advances in novel screening techniques and therapeutic directions, the prognosis of heart failure (HF) remains strikingly poor around the

\footnotetext{
*Correspondence: pedro.pallangyo@gmail.com

1 Unit of Research, Jakaya Kikwete Cardiac Institute, P.O Box 65141, Dar es Salaam, Tanzania

Full list of author information is available at the end of the article
}

globe particularly in the developing nations [2-7]. Owing to its chronic nature, clinical management of HF necessitate long-term use of several drugs to reduce morbidity [8-10] and mortality [11-13]. However, universally low prescription rates of such drugs among patients who require them is observed [14].

Despite of all developments in HF management, adherence plays a pivotal role in attaining maximal therapeutic benefits. Nevertheless, regardless of the assessment tool used or population studied, adherence rates are consistently suboptimal across studies making it a significant public health issue [15-25]. Poor adherence to prescribed 
regimens is pervasive and results in preventable hospitalizations, premature deaths and unnecessary health care expenditure regardless of the underlying cardiovascular etiology [15-26]. There is dearth of information regarding medication adherence among heart failure population in Tanzania and Sub-Saharan Africa at large. In this prospective cohort study, we sought to explore the adherence pattern, associated factors and outcomes among hospitalized heart failure patients in a tertiary hospital in Tanzania.

\section{Main text \\ Methods \\ Recruitment process and definition of terms}

All patients who were hospitalized at Jakaya Kikwete Cardiac Insitute (a tertiary care public teaching hospital) between March and October 2018 with established diagnosis of heart failure (for at least 3 months' prior enrollment) were consecutively enrolled for this study. Sociodemographic, clinical, laboratory, echocardiographic, and adherence data were gathered using a structured questionnaire during the hospital admission of enrollment. Framingham criteria was used to screen participants for heart failure symptoms and a 2-dimensional echocardiography was utilized for diagnosis reconfirmation. Renal functions were estimated using the Modification of Diet in Renal Disease equation and estimated glomerular filtration rate (eGFR) value of $<60 \mathrm{~mL} /$ $\min / 1.73 \mathrm{~m}^{2}$ was used to define renal dysfunction. Diagnosis of anemia utilized the WHO criteria i.e. Hemoglobin $(\mathrm{Hb})$ concentration of $<13.0 \mathrm{~g} / \mathrm{dL}$ and $<12.0 \mathrm{~g} /$ $\mathrm{dL}$ for males and females respectively. Diabetes was defined by fasting blood glucose levels $\geq 7.0 \mathrm{mmol} / \mathrm{L}$ or use of glucose lowering agents. Hypertension was defined as systolic blood pressure (SBP) $>140 \mathrm{mmHg}$ and/or diastolic blood pressure (DBP) $>90 \mathrm{mmHg}$ or use of antihypertensive medications. Total cholesterol level greater than $6.2 \mathrm{mmol} / \mathrm{L}$ was used to define dyslipidemia. Hyponatremia, hypokalemia, hypocalcemia, and hypomagnesemia were defined by concentrations $<135 \mathrm{mmol} / \mathrm{L},<3.5 \mathrm{mmol} / \mathrm{L},<2.1 \mathrm{mmol} / \mathrm{L}$ and $<0.7 \mathrm{mmol} / \mathrm{L}$ respectively. Potassium levels $>5.0 \mathrm{mmol} / \mathrm{L}$ was used to denote hyperkalemia. We assessed adherence based on the last time a participant last took her heart failure medications. For the purpose of this study, we defined good adherence as intake of all prescribed heart failure medications within $72 \mathrm{~h}$ before the admission of recruitment.

\section{Follow-up and study outcomes}

Follow-up was conducted through scheduled weekly phone calls and continued through April 2019 with a predetermined stopping point providing a maximum of 180 days of follow-up for each patient after enrollment. Data was censored after completion of follow-up or death, whichever occurred first. A participant was deemed lost to follow-up when despite all attempts couldn't be reached through phone numbers provided. Our primary outcome measures were rehospitalization and all-cause mortality. We defined rehospitalization as any cardiovascular-related hospital admission following a successful discharge from the hospitalization of enrollment. Early mortality was defined as death during the hospitalization of enrollment.

\section{Statistical analysis}

All statistical analyses utilized STATA v11.0 software. Pearson Chi square and Student's T-test were used to compare categorical and continuous variables respectively. Logistic regression analyses was used to assess for factors associated with adherence and predictors of rehospitalization. Factors included in our logistic regression model included age, sex, education level, marital status, employment status, residence, comorbidities and possession of health insurance. Based on their adherence status, participants were compared with respect to survival using Cox proportional-hazards regression model. Differences in survival between the low- and high-adherence groups were compared using the log-rank test. We report Odds ratio (OR), Relative risk (RR) and Hazard ratio (HR) with $95 \%$ confidence intervals $(\mathrm{CI})$ and $\mathrm{p}$-values where appropriate. All tests were 2 -sided and $\mathrm{p}<0.05$ was used to denote statistical significance.

\section{Results \\ Study population}

A total of 459 heart failure patients met the inclusion criteria and were enrolled into this study. During follow-up, $40(8.7 \%)$ participants exited; 5 due to incomplete key data and 35 were lost to follow-up. Table 1 displays the baseline characteristics of participants. The mean age of our heart failure cohort was $46.4 \pm 18.9$ years, there was female preponderance $(56.6 \%)$ and over two-thirds of all participants resided in urban areas. The mean BMI was $25.1 \pm 5.2$ and $39.4 \%$ of patients were overweight or obese. About 7.2\% of participants were in NYHA functional class II while classes III and IV constituted 36.5\% and $56.3 \%$ respectively. Heart failure with reduced ejection fraction (HFrEF) was present in $284(67.8 \%)$ of participants while 135 (32.2\%) had preserved systolic functions (HFpEF). Over a half (52.7\%) of participants had a history of hypertension, $13.6 \%$ had diabetes, $6.7 \%$ were infected with HIV, $51.3 \%$ had renal insufficiency and $72.1 \%$ were anemic. Echocardiography revealed hypertensive heart disease was the predominant cause of $\mathrm{HF}$ 
Table 1 Baseline characteristics of participants $(N=419)$

\begin{tabular}{|c|c|c|c|c|}
\hline Characteristic & $\begin{array}{l}\text { All } \\
(\mathrm{N}=419)\end{array}$ & $\begin{array}{l}\text { Poor adherence } \\
(n=313)\end{array}$ & $\begin{array}{l}\text { Good adherence } \\
(n=106)\end{array}$ & $\mathrm{p}$-value \\
\hline Age & $46.4(18.9)$ & $45.5(19.0)$ & 49.1 (18.6) & 0.09 \\
\hline \multicolumn{5}{|l|}{ Age groups } \\
\hline$<30$ & $103(24.6 \%)$ & $82(26.2 \%)$ & $21(19.8 \%)$ & 0.19 \\
\hline $30-50$ & $129(30.8 \%)$ & $96(30.7 \%)$ & $33(31.1 \%)$ & 0.94 \\
\hline$>50$ & $187(44.6 \%)$ & 135 (43.1\%) & $52(49.1 \%)$ & 0.28 \\
\hline \multicolumn{5}{|l|}{ Sex } \\
\hline Male & $182(43.4 \%)$ & $139(44.4 \%)$ & $43(40.6 \%)$ & 0.5 \\
\hline Female & $237(56.6 \%)$ & $174(55.6 \%)$ & $63(59.4 \%)$ & \\
\hline \multicolumn{5}{|l|}{ Residence } \\
\hline Urban & $283(67.5 \%)$ & 197 (62.9\%) & $86(81.1 \%)$ & 0.001 \\
\hline Rural & $136(32.5 \%)$ & $116(37.1 \%)$ & $20(18.9 \%)$ & \\
\hline \multicolumn{5}{|l|}{ Marital status } \\
\hline Single & $100(23.9 \%)$ & $82(26.2 \%)$ & $18(17.0 \%)$ & 0.05 \\
\hline Married & $296(70.6 \%)$ & $213(68.1 \%)$ & $83(78.3 \%)$ & 0.05 \\
\hline Divorced/widowed & $23(05.5 \%)$ & $18(05.7 \%)$ & $5(04.7 \%)$ & 0.67 \\
\hline \multicolumn{5}{|l|}{ Education } \\
\hline None & $16(03.8 \%)$ & $12(03.9 \%)$ & $4(03.8 \%)$ & 0.96 \\
\hline Primary & $295(70.4 \%)$ & $248(79.2 \%)$ & $47(44.3 \%)$ & $<0.001$ \\
\hline Secondary & 68 (16.2\%) & $36(11.5 \%)$ & $32(30.2 \%)$ & $<0.001$ \\
\hline University & 40 (09.6\%) & $17(05.4 \%)$ & $23(21.7 \%)$ & $<0.001$ \\
\hline \multicolumn{5}{|l|}{ Occupation } \\
\hline None & $76(18.1 \%)$ & $47(15.0 \%)$ & $29(27.3 \%)$ & $<0.01$ \\
\hline Employed/self-employed & $311(74.3 \%)$ & $250(79.9 \%)$ & $61(57.6 \%)$ & $<0.001$ \\
\hline Retired & $32(07.6 \%)$ & $16(05.1 \%)$ & $16(15.1 \%)$ & 0.001 \\
\hline Body mass index & $25.1(05.2)$ & $24.8(04.2)$ & $26.0(07.4)$ & 0.04 \\
\hline \multicolumn{5}{|l|}{ BMI categories } \\
\hline Underweight & $11(02.6 \%)$ & $7(02.2 \%)$ & $4(03.8 \%)$ & 0.37 \\
\hline Normal & $243(58.0 \%)$ & $188(60.1 \%)$ & $55(51.9 \%)$ & 0.14 \\
\hline Overweight & $105(25.1 \%)$ & $79(25.2 \%)$ & $26(24.5 \%)$ & 0.89 \\
\hline Obese & $60(14.3 \%)$ & $39(12.5 \%)$ & $21(19.8 \%)$ & 0.06 \\
\hline \multicolumn{5}{|l|}{ Health insured } \\
\hline Yes & $93(22.2 \%)$ & $32(10.2 \%)$ & $61(57.6 \%)$ & $<0.001$ \\
\hline No & $326(77.8 \%)$ & $281(89.8 \%)$ & $45(42.4 \%)$ & \\
\hline \multicolumn{5}{|l|}{ HF etiology } \\
\hline DCM & $113(27.0 \%)$ & $78(24.9 \%)$ & $34(32.1 \%)$ & 0.15 \\
\hline $\mathrm{HHD}$ & $168(40.1 \%)$ & $134(42.8 \%)$ & $35(33.0 \%)$ & 0.08 \\
\hline RHD & $97(23.2 \%)$ & $72(23.0 \%)$ & $25(23.6 \%)$ & 0.9 \\
\hline Others & 41 (09.8\%) & 29 (09.3\%) & $12(11.3 \%)$ & 0.55 \\
\hline \multicolumn{5}{|l|}{ Comorbidities } \\
\hline Hypertension & $221(52.7 \%)$ & $171(54.6 \%)$ & $50(47.2 \%)$ & 0.19 \\
\hline Diabetes & $57(13.6 \%)$ & $39(12.5 \%)$ & $18(17.0 \%)$ & 0.24 \\
\hline HIV/AIDS & $28(06.7 \%)$ & $15(04.8 \%)$ & $13(12.3 \%)$ & 0.01 \\
\hline Renal insufficiency & $215(51.3 \%)$ & $163(52.1 \%)$ & $52(49.1 \%)$ & 0.59 \\
\hline eGFR $<15$ & $100(23.9 \%)$ & $80(25.6 \%)$ & $20(18.9 \%)$ & 0.16 \\
\hline Anemia & $302(72.1 \%)$ & $234(74.8 \%)$ & $68(64.2 \%)$ & 0.04 \\
\hline $\mathrm{Hb}<8 \mathrm{~g} / \mathrm{dL}$ & 99 (23.6\%) & 75 (24.0\%) & $24(22.6 \%)$ & 0.77 \\
\hline
\end{tabular}


Table 1 (continued)

\begin{tabular}{|c|c|c|c|c|}
\hline Characteristic & $\begin{array}{l}\text { All } \\
(\mathrm{N}=419)\end{array}$ & $\begin{array}{l}\text { Poor adherence } \\
(\mathrm{n}=313)\end{array}$ & $\begin{array}{l}\text { Good adherence } \\
(n=106)\end{array}$ & $p$-value \\
\hline \multicolumn{5}{|l|}{ NYHA class } \\
\hline ॥ & $30(07.2 \%)$ & $19(06.0 \%)$ & $11(10.4 \%)$ & 0.13 \\
\hline III & $153(36.5 \%)$ & $112(35.8 \%)$ & $41(38.7 \%)$ & 0.59 \\
\hline IV & $236(56.3 \%)$ & $182(58.2 \%)$ & $54(50.9 \%)$ & 0.19 \\
\hline \multicolumn{5}{|l|}{ Systolic functions } \\
\hline Preserved (HFpEF) & $135(32.2 \%)$ & $96(71.1 \%)$ & 39 (28.9\%) & 0.24 \\
\hline Reduced (HFrEF) & $284(67.8 \%)$ & $217(76.4 \%)$ & $67(23.6 \%)$ & \\
\hline Admission days & $14.0(13.3)$ & $13.8(13.4)$ & $14.3(12.8)$ & 0.74 \\
\hline \multicolumn{5}{|c|}{ HF-related hospitalization } \\
\hline $1 \mathrm{st}$ & $211(50.4 \%)$ & $167(53.3 \%)$ & $44(41.5 \%)$ & 0.04 \\
\hline$>1$ & $208(49.6 \%)$ & $146(46.7 \%)$ & $62(58.5 \%)$ & \\
\hline
\end{tabular}

(40.1\%) followed by dilated cardiomyopathy (27.0\%) and rheumatic heart disease (23.2\%).

\section{Medication adherence}

Overall, 337 (73.4\%) were on angiotensin converting enzyme inhibitors (ACEI), $122(26.6 \%)$ on angiotensin receptor blockers (ARB), $386(84.1 \%)$ on beta-blockers, $432(94.1 \%)$ on diuretics, $395(86.1 \%)$ on aldosterone antagonists, $166(36.2 \%)$ on inotropes and 36 (7.8\%) were on digoxin. Of the 419 participants eligible for assessment of medication adherence, 313 (74.7\%) had poor adherence and 106 (25.3\%) had good adherence. The mean number of days' participants last took medications before the index hospitalization was $17.7( \pm 6.9)$ days. Among participants with poor adherence, 254 (81.2\%) had not taken any of their anti-failure medications within the past 1 -week prior admission. Inability to afford medications was the most $(87.3 \%)$ reported reason for nonadherence. Other reported factors affecting adherence in this cohort included; medication side effects (8.1\%), forgetfulness
(53.9\%), negligence (26.0\%), local unavailability of drugs (18.9\%) and pill burden (34.4\%). Differences in age, sex, marital status, and BMI displayed similar medication adherence patterns, Table 1 . However, during bivariate analyses four characteristics including education level, residence, employment status, and health insurance possession showed significant associations with adherence, Table 2. Significant variables then underwent multivariate logistic regression analysis where possession of a health insurance was found to be the strongest associated factor for adherence (OR 8.7, 95\% CI 4.7-16.0, p <0.001), Table 2.

\section{Rehospitalization and mortality}

Overall, 208 (49.6\%) patients had a history of a prior cardiovascular-related hospitalization. Despite of similar rehospitalization rates between poor and goodadherence participants at 30 -days $(35.4 \%$ vs $27.2 \%$, $\mathrm{p}=0.12$ ) and 90 -days ( $51.8 \%$ vs $40.2 \%, \mathrm{p}=0.07$ ), patients with poor adherence had significantly higher rates of

Table 2 Factors associated with adherence

\begin{tabular}{|c|c|c|c|c|c|c|c|}
\hline Control group & Comparative group & OR & $95 \% \mathrm{Cl}$ & p-value & Adj. OR & Adj. 95\% Cl & Adj. p-value \\
\hline Age $<50$ & Age $\geq 50$ & 0.8 & $0.5-1.2$ & 0.3 & - & - & - \\
\hline Female & Male & 1.2 & $0.7-1.8$ & 0.5 & - & - & - \\
\hline$\geq$ Secondary education & $\leq$ Primary education & 5.3 & $3.3-8.6$ & $<0.001$ & 1.9 & $0.9-4.0$ & 0.07 \\
\hline Married & Single & 1.7 & $1.0-2.8$ & 0.05 & - & - & - \\
\hline Employed & No employment & 0.3 & $0.2-0.5$ & $<0.001$ & 1.2 & $0.6-2.4$ & 0.6 \\
\hline Urban & Rural & 2.5 & $1.5-4.3$ & 0.001 & 2.0 & $1.1-3.7$ & 0.03 \\
\hline No comorbidity & $\geq 1$ comorbidity & 0.9 & $0.5-1.4$ & 0.56 & - & - & - \\
\hline Health insurance & Not insured & 11.9 & $7.0-20.2$ & $<0.001$ & 8.7 & $4.7-16.0$ & $<0.001$ \\
\hline HFpEF & HFrEF & 1.3 & $0.8-2.1$ & 0.28 & - & - & - \\
\hline
\end{tabular}


rehospitalization at 180 days $(57.5 \%$ vs $43.5 \%, \mathrm{p}=0.03)$. Overall, participants with poor adherence displayed a $70 \%$ increased risk for rehospitalization compared to their counterparts with good adherence (RR 1.7, 95\% CI $1.2-2.9, \mathrm{p}=0.04)$.

177 (42.2\%) patients survived the 180-days of followup. The mean survival days was $103.3 \pm 74.8$ days and participants with good adherence (140.5 \pm 63.1 days) displayed a longer survival compared to their poor adherence ( $90.8 \pm 74.3$ days) counterparts, $\mathrm{p}<0.001$. Regardless of the assessment time, participants with poor adherence displayed superior mortality compared to those with good adherence i.e. $37.1 \%$ vs $12.3 \%, 56.6 \%$ vs $25.5 \%$, and $65.5 \%$ vs $34.9 \%$ at 30,90 , and 180 days respectively; all $\mathrm{p}<0.001$ ). Additionally, we performed subgroup analyses to assess for all-cause mortality by adherence status. In all 19 characteristics involved in subgroup analyses, participants with poor adherence had inferior survival rates compared to their counterparts with good adherence, Fig. 1. More interestingly, even within the subgroup of those who possessed a health insurance, it was observed that poor adherence participants fared worse compared to good adherence controls, (HR 1.6, 95\% CI 1.0-2.4, $\mathrm{p}=0.05)$.

\section{Discussion}

Management of heart failure is complex and multifaceted but adherence to medications remains a fundamental measure to prevent acute exacerbations [27, 28]. Despite of unwavering evidence on the efficacy of antifailure drugs, poor adherence is common and remains a significant barrier to improving clinical outcomes in heart failure population. Estimates of nonadherence in heart failure patients have varied widely $(22-90 \%)$ [18, $25,29-36]$ in the literature. In this present study, less than one-fifth of participants were categorized as having high adherence. Our rate of nonadherence is skewed to the extreme undesired end of the reported range in the literature.

With regards to reasons for poor adherence, numerous factors have predominated in various studies. For instance, in studies by Toh et al. (71\%) and Mujtaba et al. (72.7\%), poor medication instructions was the most reported factor $[25,36]$. On the other hand, studies by Aggarwal et al. and Dickson et al. found forgetfulness and comorbidities respectively as the leading factors for nonadherence $[29,32]$. In this present study, nearly $90 \%$ of nonadherent participants reported medication cost as the major barrier to their adherence. These findings are

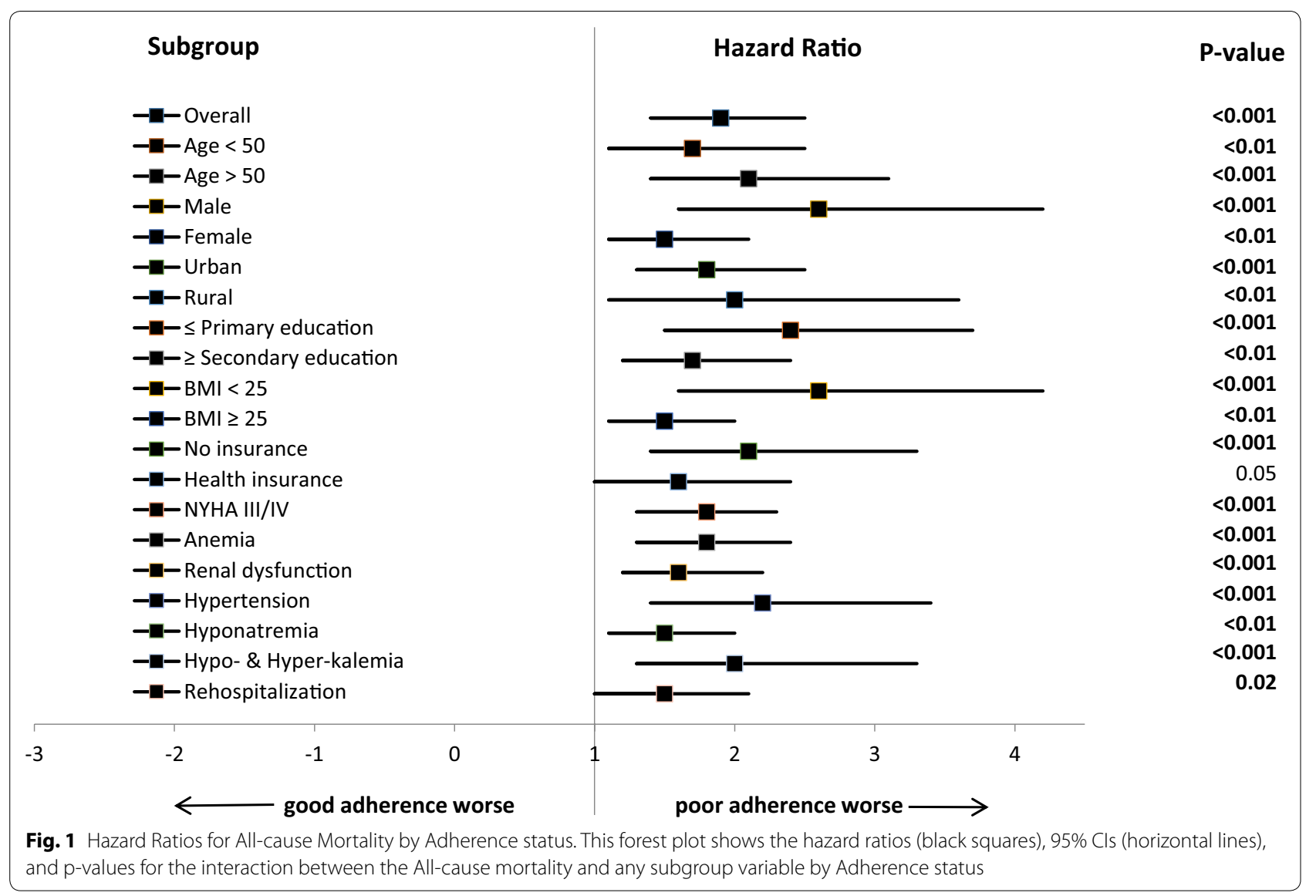


in unison with Dunlay et al. study as far as cost being the most reported factor is concerned, however it was a barrier in a significantly lesser proportion (22\%) compared to what we observed [37]. While majority of known risk factors for nonadherence are potentially modifiable, inability to comply due to poverty is not. Owing to this, improving medication adherence in impoverished societies continues to be a very difficult undertaking. It should not be forgotten that such poor societies and their already overwhelmed health sectors continue to struggle with prevention and management of the ever present infectious diseases.

Several studies have demonstrated the repercussions of poor adherence on prognosis of heart failure [16, 32, 33, 38, 39]. Moreover, numerous studies have established the prognostic benefits of interventions to improve adherence $[24,40-50]$. In this present study, nearly $60 \%$ of participants with poor adherence were rehospitalized within 6-months of enrollment. Our findings are in consonance with several other prospective studies which have produced rehospitalization rates ranging between 20 and $69 \%$ [16, 32, 33, 38, 39]. Additionally, intervention studies have uniformly shown that improved adherence is associated with reduction (3-96\%) in readmission risk [40, 41, 43, 44, 46-49]. Furthermore, systematic reviews and meta-analyses by Ruppar et al. and Unverzagt et al. revealed a $21 \%$ and $10 \%$ decreased odds of rehospitalization respectively in the adherence intervention arm [24, 50].

Survival prospects among heart failure patients remain poor all over the globe. Overall, less than half of patients in this study survived the 6-months of follow-up. Nonadherent participants displayed about three times mortality hazard compared to their adherent counterparts. Similar to our findings, intervention studies have shown mortality reduction $(2-84 \%)$ in favor of adherent participants [40-42, 44-46, 48]. Moreover, two meta-analyses that included over 50 studies each showed a $2 \%$ and $11 \%$ mortality reduction in favor of the adherence intervention arm $[24,50]$. Poor adherence was found to be the strongest predictor of early mortality in this study. To solidify on the significance of adherence in heart failure prognostication, participants with low adherence displayed significantly higher rates of primary outcomes compared to their high adherence counterparts in all subgroup analyses we conducted.

\section{Conclusions}

In conclusion, findings of this present study provide important insight pertaining to medication adherence and its potential in dictating the prognosis of heart failure patients residing in resource-limited settings. Poor adherence in patients with heart failure contributes to a considerable burden on the healthcare system above all increased rehospitalizations and mortality. These findings call for deliberate efforts to ensure that measures to assess and improve adherence are incorporated and become an integral component in routine clinical practice. Furthermore, strategies to improve health insurance acquisition including endeavours to make it a right rather than a privilege is fundamental in improving adherence especially among persons living in impoverished societies.

\section{Limitations}

Medication adherence was ascertained by self-report and thus reporting bias and recall bias could have in some way affected our findings. Prospective comparison of patients receiving adherence intervention versus control would allow a more rigorous evaluation of adherence potential in prognosticating heart failure and should be considered in the future studies in this setting.

\section{Abbreviations \\ ACE: Angiotensin converting enzyme; ARB: Angiotensin receptor blocker; BMI: Body mass index; Cl: Confidence interval; CVD: Cardiovascular disorders; DBP: Diastolic blood pressure; eGFR: Estimated glomerular filtration rate; FBG: Fast- ing blood glucose; Hb: Hemoglobin; HF: Heart failure; HFpEF: Heart failure with preserved ejection fraction; HFrEF: Heart failure with reduced ejection fraction; HR: Hazard ratio; MDRD: Modification of diet in renal disease; MMAS-8: 8-Item Morisky Medication Adherence Scale; NYHA: New York Heart Association; OR: Odd ratio; RR: Relative risk; SBP: Systolic blood pressure; WHO: World Health Organization.}

\section{Acknowledgements}

We thank the nursing and medical staff of the Jakaya Kikwete Cardiac Institute for their cooperation and active participation during this study. We extend our gratitude to all the study participants and their relatives for their willingness, tolerance and cooperation offered during the entire study duration.

\section{Authors' contributions}

PP conceived the study. JM, ZM, NM, HJS and NRH conducted all the interviews and physical examinations. Echocardiography was performed by MJ, AK, and SB. PP performed data entry and analysis. The corresponding author wrote the first draft of the manuscript, and other authors contributed to and approved it. All authors made the decision to submit the manuscript for publication. All authors assume responsibility for the accuracy and integrity of the analysis. All authors read and approved the final manuscript.

\section{Funding}

This work was funded by the Commission for Science and Technology (COSTECH) of Tanzania. The funder had no role in the design of this study, collection of data, data analysis, interpretation of results or writing of this manuscript.

\section{Availability of data and materials}

The final version of data set supporting the findings of this paper is submitted together with this manuscript to the editorial committee. All the raw data is included in this manuscript. There are no ethics restrictions preventing the sharing of the raw data.

\section{Ethics approval and consent to participate}

Participants gave written informed consent to participate in the study. The study protocol was approved by the local ethics committees (Muhimbili 
University of Health and Allied Sciences) and was conducted in accordance with the Declaration of Helsinki.

\section{Consent to publish}

Not applicable.

\section{Competing interests}

The authors declare that they have no competing interests.

\section{Author details}

${ }^{1}$ Unit of Research, Jakaya Kikwete Cardiac Institute, P.O Box 65141, Dar es Salaam, Tanzania. ${ }^{2}$ Department of Adult Cardiology, Jakaya Kikwete Cardiac Institute, P.O Box 65141, Dar es Salaam, Tanzania. ${ }^{3}$ Department of Nursing, Jakaya Kikwete Cardiac Institute, P.O Box 65141, Dar es Salaam, Tanzania.

Received: 9 January 2020 Accepted: 17 February 2020

Published online: 21 February 2020

\section{References}

1. World Health Organization. Cardiovascular diseases Fact sheet reviewed September 2016. http://www.who.int/mediacentre/factsheets/fs317/en/.

2. Kraus S, Ogunbanjo G, Sliwa K, Ntusi NAB. Heart failure in sub-Saharan Africa: a clinical approach. S Afr Med J. 2016;106(1):23-31.

3. Ntusi NB, Mayosi BM. Epidemiology of heart failure in sub-Saharan Africa. Expert Rev Cardiovasc Ther. 2009;7(2):169-80.

4. Makubi A, Hage C, Lwakatare J, et al. Contemporary aetiology, clinical characteristics and prognosis of adults with heart failure observed in a tertiary hospital in Tanzania: the prospective Tanzania Heart Failure (TaHeF) study. Heart. 2014;100(16):1235-41.

5. Pallangyo P, Fredrick F, Bhalia S, et al. Cardiorenal anemia syndrome and survival among heart failure patients in Tanzania: a prospective cohort study. BMC Cardiovasc Disord. 2017;17:59.

6. Parmar KR, Xiu PY, Chowdhury MR, et al. In-hospital treatment and outcomes of heart failure in specialist and non-specialist services: a retrospective cohort study in the elderly Open. Heart. 2015;2:e000095.

7. Karaye KM, Sani MU. Factors associated with poor prognosis among patients admitted with heart failure in a Nigerian tertiary medical centre: a cross-sectional study. BMC Cardiovasc Disord. 2008;8:16.

8. Gheorghiade M, Patel K, Filippatos G, et al. Effect of oral digoxin in highrisk heart failure patients: a pre-specified subgroup analysis of the DIG trial. Eur J Heart Fail. 2013;15(5):551-9.

9. Zannad F, McMurray JJ, Krum H, van Veldhuisen DJ, Swedberg K, Shi H, et al. Eplerenone in patients with systolic heart failure and mild symptoms. N Engl J Med. 2011;364(1):11-21.

10. Metra M, Teerlink JR, Voors AA, et al. Vasodilators in the treatment of acute heart failure: what we know, what we don't. Heart Fail Rev. 2009;14:299-307.

11. Konstam MA, Rousseau MF, Kronenberg MW, Udelson JE, Melin J, Stewart $D$, et al. Effects of the angiotensin converting enzyme inhibitor enalapril on the long-term progression of left ventricular dysfunction in patients with heart failure. SOLVD Investigators. Circulation. 1992:86(2):431-8.

12. Pfeffer MA, Swedberg K, Granger CB, Held P, McMurray JJ, Michelson EL, et al. Effects of candesartan on mortality and morbidity in patients with chronic heart failure: the CHARM-Overall programme. Lancet. 2003:362(9386):759-66.

13. Haas SJ, Vos T, Gilbert RE, Krum H. Are beta-blockers as efficacious in patients with diabetes mellitus as in patients without diabetes mellitus who have chronic heart failure? A meta-analysis of large-scale clinical trials. Am Heart J. 2003;146:848-53.

14. Yusuf S, Islam S, Chow CK, et al. Use of secondary prevention drugs for cardiovascular disease in the community in high-income, middleincome, and low-income countries (the PURE Study): a prospective epidemiological survey. Lancet. 2011;378(9798):1231-43.

15. Simpson SH, Eurich DT, Majumdar SR, et al. A metaanalysis of the association between adherence to drug therapy and mortality. BMJ. 2006:333:18-26.
16. Osterberg L, Blaschke T. Adherence to medication. N Engl J Med. 2005;353:487-97.

17. Ho PM, Bryson CL, Rumsfeld JS. Medication adherence: its importance in cardiovascular outcomes. Circulation. 2009;119:3028-35.

18. Oosterom-Calo R, van Ballegooijen AJ, Terwee CB, et al. Determinants of adherence to heart failure medication: a systematic literature review. Heart Fail Rev. 2013;18:409-27.

19. Juarez DT, Williams $A E$, Chen $C$, et al. Factors affecting medication adherence trajectories for patients with heart failure. Am J Manag Care. 2015;21(3):197-205

20. Molloy GJ, O'Carroll RE, Witham MD, et al. Interventions to enhance adherence to medications in patients with heart failure: a systematic review. Circ Heart Fail. 2012;5:126-33.

21. Fitzgerald AA, Powers JD, Ho PM, et al. Impact of medication nonadherence on hospitalizations and mortality in heart failure. J Card Fail. 2011;17(8):664-9.

22. Shah D, Simms K, Barksdale DJ, Wu JR. Improving medication adherence of patients with chronic heart failure: challenges and solutions. Res Rep Clin Cardiol. 2015;6:87-95

23. Ruppar TM, Delgado JM, Temple J. Medication adherence interventions for heart failure patients: a meta-analysis. Eur J Cardiovasc Nurs. 2015;14(5):395-404.

24. Ruppar TM, Cooper PS, Mehr DR, et al. Medication adherence interventions improve heart failure mortality and readmission rates: systematic review and meta-analysis of controlled trials. J Am Heart Assoc. 2016;5(6):e002606.

25. Toh CT, Jackson B, Gascard DJ, et al. Barriers to medication adherence in chronic heart failure patients during home visits. J Pharm Pract Res. 2010:40:27-30.

26. Sabate' E. Adherence to long-term therapies: evidence for action Geneva: World Health Organization; 2003.

27. Kemp C, Conte J. The pathophysiology of heart failure. Cardiovasc Pathol. 2012;21(5):365-71.

28. O'Connor CM, Stough WG, Gallup DS, Hasselblad V, Gheorghiade M. Demographics, clinical characteristics, and outcomes of patients hospitalized for decompensated heart failure: observations from the IMPACT-HF registry. J Card Fail. 2005;11(3):200-5.

29. Aggarwal B, Pender A, Mosca L, Mochari-Greenberger $\mathrm{H}$. Factors associated with medication adherence among heart failure patients and their caregivers. J Nurs Educ Pract. 2015;5(3):22-7.

30. Zhang Y, Wu SH, Fendrick AM, Baicker K. Variation in medication adherence in heart failure. JAMA Intern Med. 2013;173(6):468-70.

31. Knafl GJ, Riegel B. What puts heart failure patients at risk for poor medication adherence? Patient Prefer Adherence. 2014;17(8):1007-18.

32. Dickson W, Knafl GJ, Riegel B. Predictors of medication nonadherence differ among black and white patients with heart failure. Res Nurs Health. 2015:38(4):289-300.

33. Wu JR, Frazier SK, Rayens MK, et al. Medication adherence, social support, and event-free survival in patients with heart failure. Health Psychol. 2013;32(6):637-46.

34. Alakhali KM, Daniel PS, Noohu AM, Sirajudeen SA. Patient medication adherence and physician prescribing among congestive heart failure patients of Yemen. Indian J Pharm Sci. 2013;75(5):557-62.

35. Lee D, Mansi I, Bhushan S, Parish R. Non-adherence in at-risk heart failure patients: characteristics and outcomes. J Nat Sci. 2015;1(5):e95.

36. Mujtaba SF, Masood T, Saad M. Reasons of medical noncompliance in heart failure patients. Pak Heart J. 2010;43:3-4.

37. Dunlay SM, Eveleth JM, Shah ND, et al. Medication adherence among community-dwelling patients with heart failure. Mayo Clin Proc. 2011;86(4):273-81.

38. Albert NM. Improving medication adherence in chronic cardiovascular disease. Crit Care Nurse. 2008;28(5):54-64 (quiz 65).

39. Leventhal MJ, Riegel B, Carlson B, De GS. Negotiating compliance in heart failure: remaining issues and questions. Eur J Cardiovasc Nurs. 2005;4:298-307.

40. Antonicelli $R$, Testarmata $P$, Spazzafumo $L$, et al. Impact of telemonitoring at home on the management of elderly patients with congestive heart failure. J Telemed Telecare. 2008:14:300-5.

41. Antonicelli R, Mazzanti I, Abbatecola AM, Parati G. Impact of home patient telemonitoring on use of b-blockers in congestive heart failure. Drugs Aging. 2010;27:801-5. 
42. Assyag P, Renaud T, Cohen-Solal A, et al. RESICARD: East Paris network for the management of heart failure: absence of effect on mortality and rehospitalization in patients with severe heart failure admitted following severe decompensation. Arch Cardiovasc Dis. 2009;102:29-41.

43. Bisharat $\mathrm{B}, \mathrm{Hafi} \mathrm{L}$, Baron-Epel $\mathrm{O}$, et al. Pharmacist counselling to cardiac patients in Israel prior to discharge from hospital contribute to increasing patient's medication adherence closing gaps and improving outcomes. J Transl Med. 2012;10:34.

44. Bocchi EA, Cruz F, Guimaraes G, et al. Long-term prospective, randomized, controlled study using repetitive education at six-month intervals and monitoring for adherence in heart failure outpatients: the REMADHE trial. Circ Heart Fail. 2008;1:115-24.

45. DeWalt DA, Schillinger D, Ruo B, et al. Multisite randomized trial of a single-session versus multisession literacy sensitive self-care intervention for patients with heart failure. Clin Trial Regist. 2012;125:2854-62.

46. Falces C, Lopez-Cabezas C, Andrea R, et al. Intervencion educativa para mejorar el cumplimiento del tratamiento y prevenir reingresos en pacientes de edad avanzada con insuficiencia cardiaca [An educative intervention to improve treatment compliance and to prevent readmissions of elderly patients with heart failure]. Med Clin (Barc). 2008;131:452-6.
47. Ferrante D, Varini S, Macchia A, on behalf of the GESICA Investigators, et al. Long-term results after a telephone intervention in chronic heart failure: DIAL (randomized trial of phone intervention in chronic heart failure) follow-up. J Am Coll Cardiol. 2010;56:372-8.

48. Powell LH, Calvin JE Jr, Richardson D, et al. Self-management counselling in patients with heart failure: the heart failure adherence and retention randomized behavioral trial. JAMA. 2010;304:1331-8.

49. Shively MJ, Gardetto NJ, Kodiath MF, et al. Effect of patient activation on self-management in patients with heart failure. J Cardiovasc Nurs. 2013;28:20-34.

50. Unverzagt S, Meyer G, Mittmann S, et al. Improving Treatment Adherence in Heart Failure: a Systematic Review and Meta-analysis of Pharmacological and Lifestyle Interventions. Dtsch Arztebl Int. 2016;113(25):423-30.

\section{Publisher's Note}

Springer Nature remains neutral with regard to jurisdictional claims in published maps and institutional affiliations.
Ready to submit your research? Choose BMC and benefit from:

- fast, convenient online submission

- thorough peer review by experienced researchers in your field

- rapid publication on acceptance

- support for research data, including large and complex data types

- gold Open Access which fosters wider collaboration and increased citations

- maximum visibility for your research: over $100 \mathrm{M}$ website views per year

At BMC, research is always in progress.

Learn more biomedcentral.com/submissions 